\title{
A Mixed-Methods Analysis of Supports and Barriers for Rural College Students
}

Stephen V. Flynn, Counseling and Marriage and Family Therapy, Plymouth State University

Eric M. Laflamme, Department of Mathematics, Plymouth State University

Danica G. Hays, College of Education, University of Nevada-Las Vegas

This article outlines an exploratory sequential mixed-methods study on the environmental supports and barriers for students attending a rural college. Data collected through six focus group interviews $(N=19)$ indicated 20 themes associated with student success; faculty practices with students; administrative issues; or president, cabinet, and board of trustee vision. An 86-item survey, grounded in qualitative themes, yielded evidence of convergence and divergence for an initial sample of 256 students.

Keywords: phenomenology, students, rural, retention

Author Note: The authors would like to acknowledge Casey McCabe and Sarah Gahm for their contributions to this article. 
Rural and manufacturing-dominated regions of the United States (e.g., eastern Kentucky, Appalachia, Mississippi Delta, New England's North Country) have faced decades of insufficient economic growth, population decline, job loss, increased substance abuse, and a lack of educational opportunity (Hamilton, Fogg, \& Grimm, 2017). Many rural colleges situated in these settings face similar issues of student decline, substance abuse problems, and financial stagnation (Moody's Investors Service, 2012; Selingo, 2013). There is evidence that federal Pell Grant programs have greatly assisted needy rural students and colleges by covering the cost of college attendance (Bradley, 2012), however recent cuts in state appropriations have negatively affected this grant program, creating yet another barrier for disadvantaged rural colleges and the students they serve (Koh, Katsinas, Bray, \& Hardy, 2019). Furthermore, unique academic persistence and retention issues are exacerbated for "at-risk" student populations, including: first-generation college students (Bryan \& Simmons, 2009), students from lower socioeconomic backgrounds (Bloom, 2009), and students of color (Linley, 2018) within rural colleges. To combat these disparities, some rural colleges are bolstering efforts to understand and increase support services for these populations (Birx, et al., 2013).

Postsecondary disparities and challenges for at-risk students (e.g., lack of institutional capacity, insufficient commitment of resources) have been a focus in student affairs research and scholarship for the past decade (e.g., Flynn, Duncan, \& Jorgensen, 2012;; Bloom, 2009; Lowinger et al., 2016; Sandoz, Kellum, \& Wilson, 2017; Sriram, Glanzer, $\&$ Allen, 2018). To forge successful educational pathways for students attending a rural college (Bryan \& Simmons, 2009), particularly those within at-risk populations, college personnel have bolstered multiple aspects of the higher education experience. These aspects include academic self-efficacy (Lowinger et al., 2016), development of learning communities and service learning experiences (Beckowski, Gebauer, \& Arminio, 2018), academic psychological preparedness (Ridenour, 2015), academic motivation (Troiano et al., 2018), transitioning from secondary to postsecondary educational settings (Flynn, et al., 2012), college access 
(Bloom, 2009), student grit (Sriram et al., 2018), and Acceptance and Commitment Training (Sandoz et al., 2017). Despite this attention, there lacks information about the supports and barriers to advise college stakeholders serving rural colleges.

While we found an investigation into family involvement for rural college students (Bryan \& Simmons, 2009) and the transition and retention experiences of rural students from diverse backgrounds (Flynn, et al., 2012), we could not locate an empirically-based investigation into the supports and barriers that students attending a rural college experience. The purpose of this investigation was to identify the environmental supports and barriers for at-risk students in a rural college setting. The overarching research question for the present study was: are the supports and barriers for at-risk rural college students identified by college stakeholders, generalizable to an initial sample of students attending a rural college? Sub-questions linked with each phase of the sequential exploratory design were as follows: (a) what do college stakeholders perceive are the supports and barriers for at-risk student populations residing in a rural college setting (qualitative phase)?; (b) to what degree does an initial sample of students agree with stakeholderidentified environmental supports and barriers (quantitative phase)?; and (c) is there a relationship between level of item agreement with survey item type (integrated phase)?

\section{Method}

A sequential exploratory mixed-methods design (Creswell \& Plano Clark, 2012) was used to understand the environmental supports and barriers for at-risk student populations in a rural college setting. We analyzed stakeholder focus group interviews with a phenomenological approach and corroborated the qualitative findings through disseminating a survey, based on all of the qualitative themes, to the student body. Specifically, through creating survey questions based on qualitative primary themes and meaning units, we developed survey questions to measure student agreement and to facilitate a shared understanding across both qualitative and quantitative methods (Mbuagbaw et al., 2014). 


\section{Context}

The study was conducted at a medium-sized residential public institution located in the northeastern United States. The college is situated in a rural community with a population of approximately 3,800 people. The rural college's student population was approximately 6,300 $(4,100$ undergraduates). Admissions data indicated that about $43.1 \%$ of the student population were first-generation college students, $32.6 \%$ (1,351 students) of undergraduates were eligible for a Federal Pell Grant Award, and of 3,760 students reporting their ethnicity, 9.6\% noted ethnicities other than White.

\section{Data Sources}

The study included two samples (stakeholder groups, students) with one sample engaged in each study phase (see Table 1 for sample demographics). After receipt of IRB approval, the principal investigator (PI; i.e., first author) identified individuals $(\mathrm{N}=19)$ from three stakeholder groups (i.e., 7 administration, 6 faculty, 6 student; Sample 1) to participate in 2 one-hour focus group interviews each (i.e., six total) for the qualitative phase. All qualitative focus group participants completed both interviews. To be eligible, stakeholders had to identify as a currently enrolled, fulltime, undergraduate or graduate student; a full-time faculty member; or an administrator. Furthermore, administration participants were selected if they served in a role connected to the student population and if they stated that they have weekly contact with "at-risk" students (e.g., first-generation college students, students from lower socioeconomic backgrounds, students of color). Sample 2 (i.e., survey sample) consisted of an initial (pilot) sample of 256 students enrolled in the college who completed an electronic survey; the survey was disseminated four times to the entire undergraduate student body. Given that the literature on at-risk students in a rural college setting is sparse, and because being a student in a rural college setting is itself a risk factor (Bryan \& Simmons, 2009), the research team considered the survey sample to be diverse (see Hamilton, Fogg, \& Grimm, 2017; Selingo, 2013). 


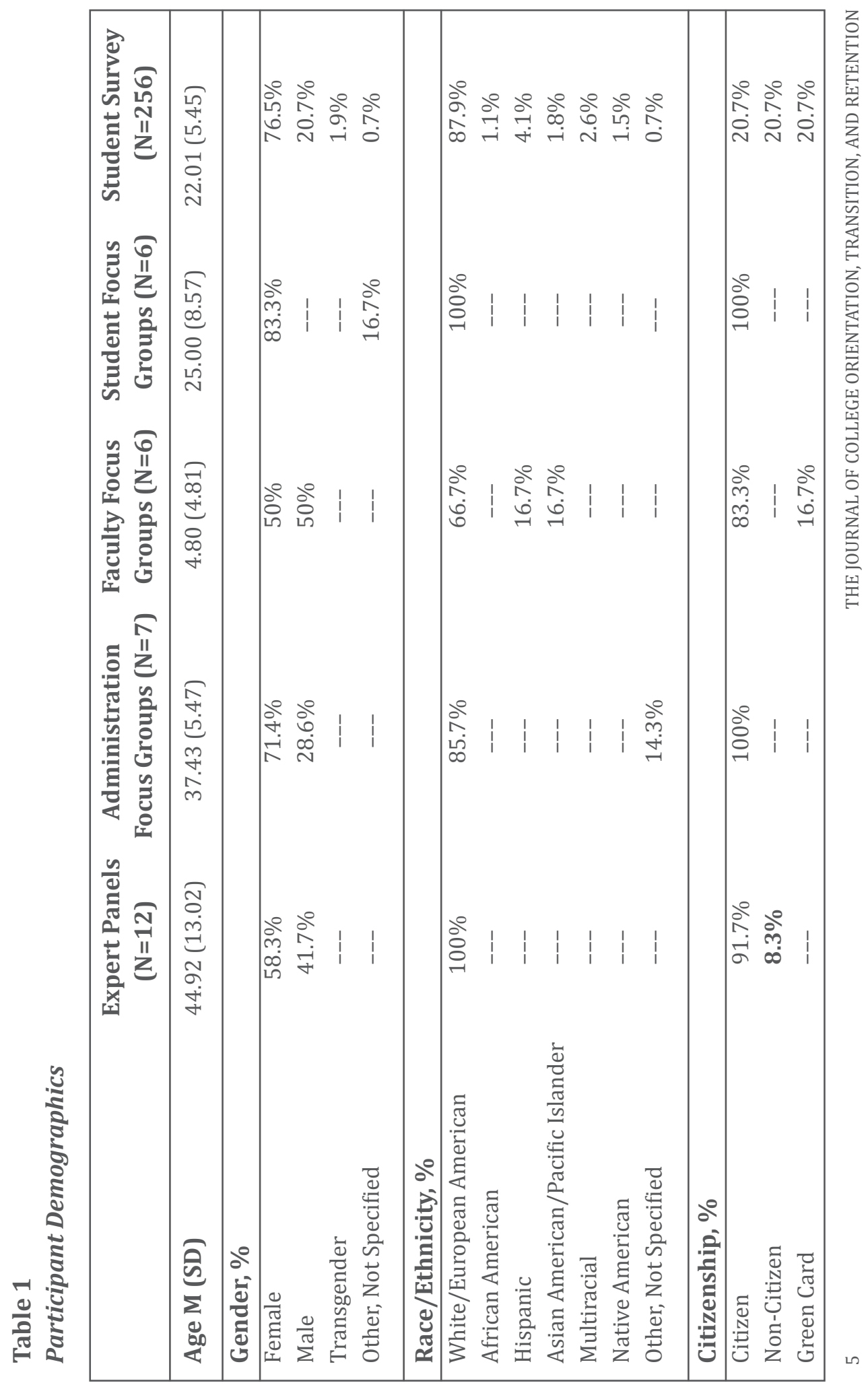




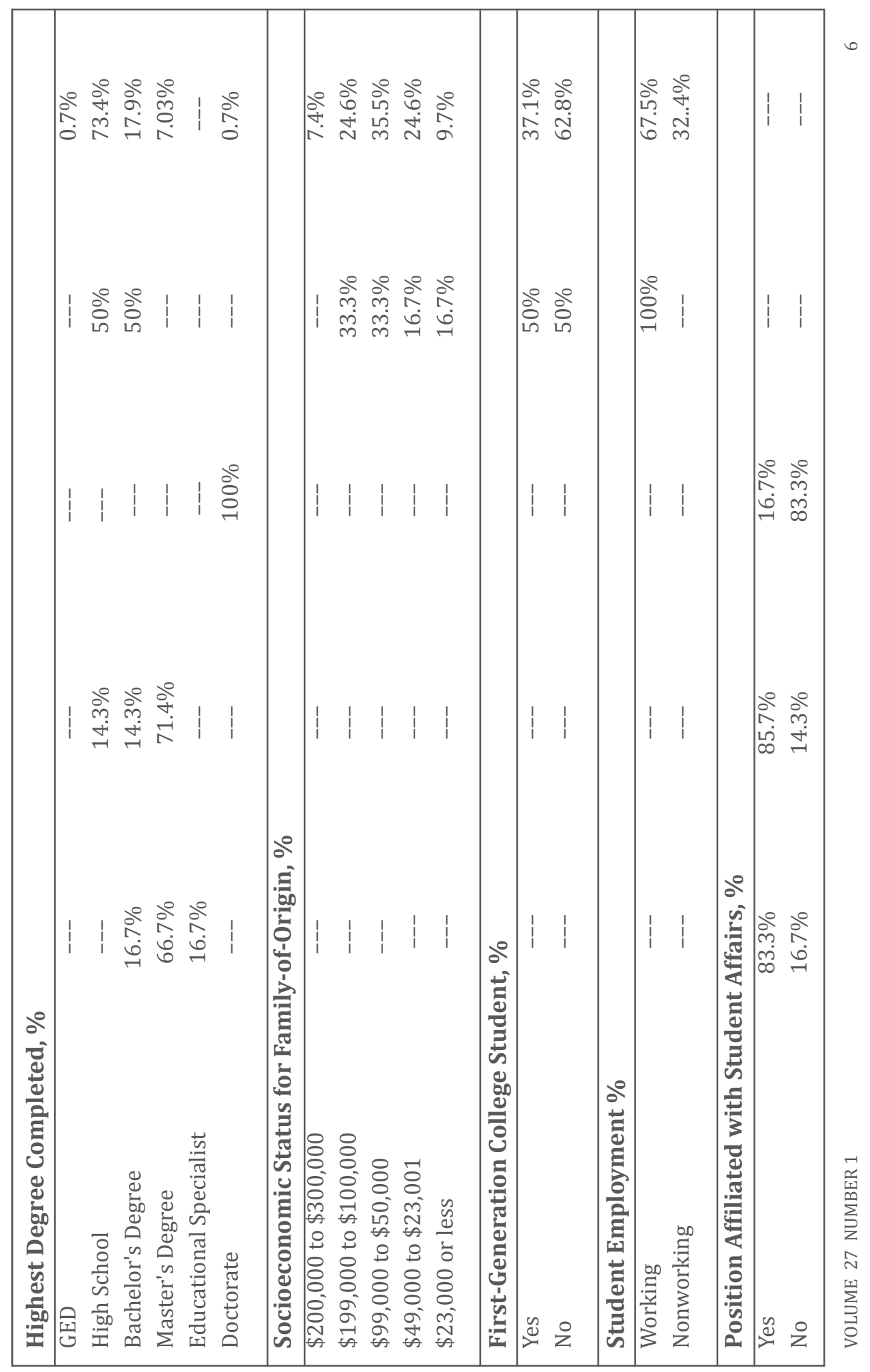




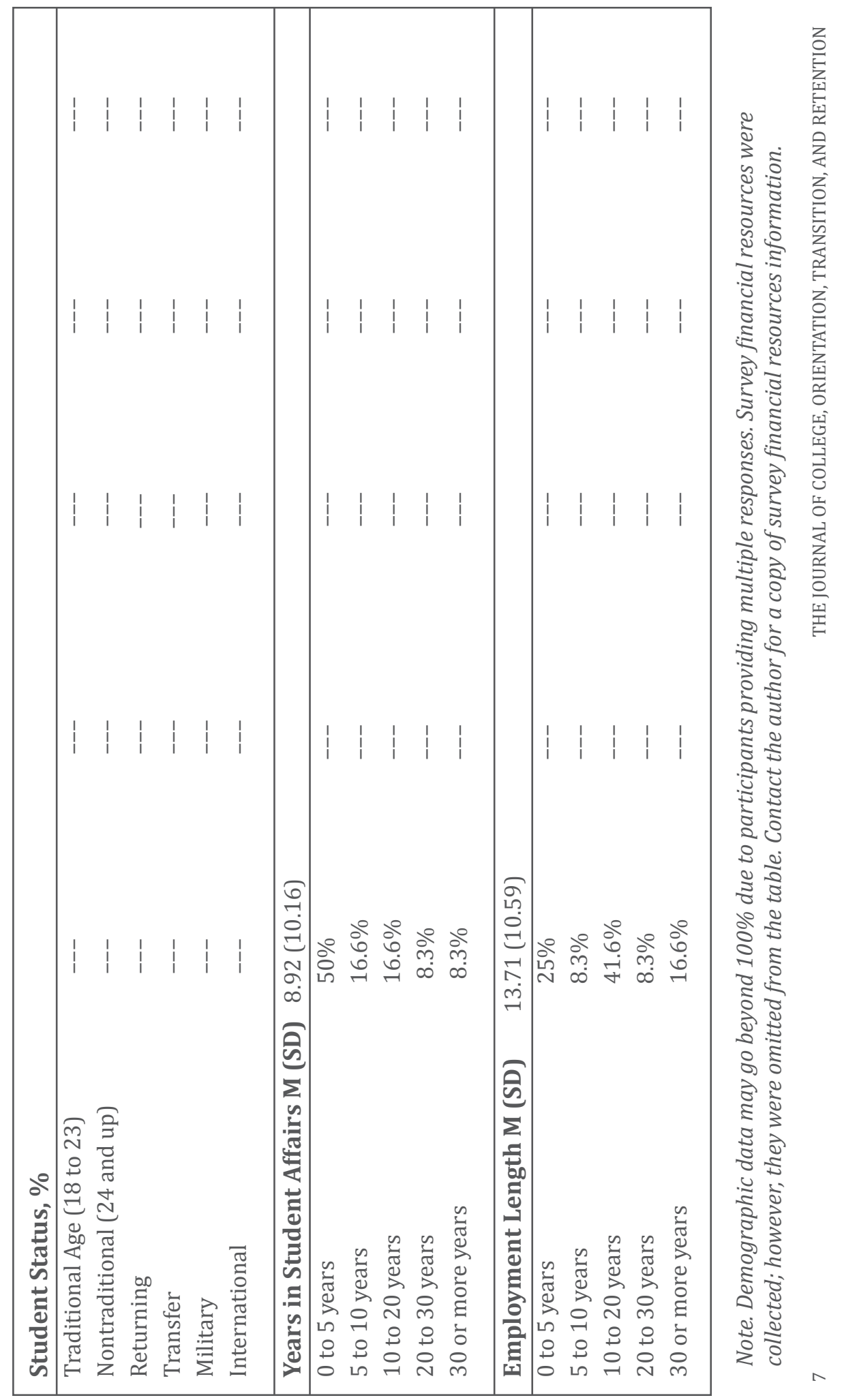




\section{Research Team}

The team was comprised of three researchers with collective experience in phenomenological, survey, and mixed methods designs. The first and second authors had prolonged engagement in the research site as tenure-track faculty members with an average of 6 years working at the college.

To strengthen the study's rigor, the PI identified an expert panel of 12 professionals, representing various academic positions, to participate as co-researchers and provide ratings that served as content validity evidence for the two study phases. All expert panel participants participated in both components of the study. Prior to the initial qualitative phase, the panelists evaluated two focus group interview protocols developed by the PI from the student affairs literature. The panelists then rated the degree to which focus group themes from the initial qualitative phase were infused within a student survey used in the quantitative phase of the study.

\section{Data Methods}

Focus group interview guides. Two interview guides were used for each stakeholder group (one guide per focus group interview). The sample of focus group questions presented below were followed up with probes. Sample questions were as follows: (a) From your experience, do you believe [college] is an inclusive community that promotes equality for all students?; (b) How would you identify and describe the population of students that has, from your perspective, struggled the most at [college]?; (c) What group of students do you see thriving at [college]?; and (d) How were you prepared (emotionally, socially, and academically) to attend a four-year university? What resources have you used, or would like to see created, to improve your success at [college]?

Student survey. The research team developed a survey from the qualitative themes identified in the qualitative phase as a way to evaluate the degree to which themes were present for the student sample. Students rated each item using a 5-point Likert scale ranging from (1) strongly disagree to (5) strongly agree; higher ratings indicated that the statement 
was true some (agree; 4) or most of the time (strongly agree; 5). Prior to survey administration, the expert panel assessed the content validity of 99 potential items, relative to the 20 primary and 129 secondary themes of the qualitative phase. All potential survey items were presented together to the expert panel.

\section{Data Analysis}

Qualitative phase. Using a 8-point relevance scale (Davis, 1992), the expert panel rated 31 potential questions; the PI retained questions with content validity index (CVI) estimates above 0.75 (see Ruperto et al., 2008), yielding 18 of 31 Focus Group 1 questions and 15 of 31 Focus Group 2 questions. For the retained items, expert ratings on the itemlevel CVIs (i.e., average score of all experts for one item) ranged from 0.75 to 0.92 with an overall mean item-level CVI score of 0.83 for the Focus Group 1 and Focus Group 2 questions; domain-level (i.e., average score of all experts for items in a stakeholder group) CVI estimates ranged from 0.82 to 0.88 . Faculty-related questions within Focus Group 1 (0.84) and Focus Group 2 (0.83) interview guide had the highest domain level scores. Administration Focus Group 1 and Group 2 interview guides had domain level scores of 0.83 . Student Focus Group 1 and Group 2 interview guides had domain level scores of 0.82 and 0.83 respectively. The overall expert proportion scores (i.e., the proportion of items given a rating of 5 or more by the 12 raters involved) ranged from 0.35 to 1.00 . The overall mean expert proportion score for the FFG was 0.78 , and the SFG score was 0.72 (Lynn, 1986).

The PI conducted two focus group interviews with each stakeholder group to enhance study rigor via persistent observation and member checking methods (see Hays \& Singh, 2012). All focus group content was audio recorded and transcribed. The PI conducted Focus Group 1 with each stakeholder group (sequence of administration, faculty, and then student) prior to Focus Group 2. Focus group interview data were analyzed by the research team using the following phenomenological analysis steps (i.e., Moustakas, 1994): reviewing transcripts and determining significant statements (i.e., horizontalization), identifying clusters of meaning, 
forming primary and secondary themes, identifying and then confirming textural descriptions and overarching domains (i.e., structural description) using the first and second focus groups, respectively.

Quantitative phase. Expert ratings for an initial 99-item survey using an 8-point relevance scale yielded item-level CVI estimates ranging from 0.53 to 0.98 with a mean item-level CVI estimate of 0.78 . The PI eliminated 13 items, which had CVI estimates ranging from 0.57 to 0.67 ; the mean item-level CVI estimate for the remaining items was 0.82 . The expert proportion scores for the 99-item survey ranged from 0.51 to 1.00 (86-item survey: 0.61 to 1.00 ). The overall mean expert proportion score for the expert panel CVI (survey) was 0.76; the mean for the 86-item survey was 0.83 .

Integrated analysis. To derive richer meaning from the qualitative and quantitative phases, the research team correlated the data to generate meta inferences and divergent inferences. Further, we conducted a logistic regression on the relationship between the survey question type and the level of item agreement. According to Tashakkori and Teddlie (2008), a "meta inference is an overall conclusion, explanation or understanding developed through an integration of the inferences obtained from the qualitative and quantitative strands of a mixed method study" (p. 101). For the study, a meta inference was a survey item (based on qualitative findings) with which most ( $\geq 75 \%$ ) student survey respondents agreed or strongly agreed. A divergent inference was a survey question with which most ( $\geq 75 \%$ ) student survey respondents disagreed or strongly disagreed.

For logistic regression analysis, all parameter estimation was performed via maximum likelihood estimation using R statistical software (R Core Team, 2013); Wald tests were performed using the aod package (Lesnoff \& Lancelot, 2012). To simplify the analysis, each survey response was classified as either a 1 or $0(1=y e s ; 0=n o)$ based on whether the majority of respondents strongly agreed or disagreed with the question. Next, the research team simplified the 86 survey items by grouping them into three categories linked with relevant qualitative themes. Specifically, these categories correspond to questions related to (a) accessibility and importance of educational and campus-based resources (Themes 3, 10, 12, 
20); (b) faculty and staff experiences, values, and interventions (Themes $5,8,6,9,7,15,16)$; and (c) needs, culture, and conduct of students and communities (Themes 1, 2, 4, 11, 13, 14, 17, 18).

\section{Strategies for Trustworthiness}

The research team maximized the trustworthiness of the qualitative study phase using strategies congruent with the phenomenological tradition (see Hays \& Singh, 2012) to provide evidence of credibility, dependability, transferability, and confirmability. Specifically, key strategies used were as follows: (a) prolonged engagement with data sources and setting; (b) use of multiple investigators (i.e., research team, expert panel) who independently and consensus-coded data; (c) use of multiple data sources (i.e., stakeholder groups, students) to triangulate the findings; and (d) researcher reflexivity through bracketing (i.e., researchers suspending judgement and focusing on analysis), journaling (i.e., researchers writing down bias and reflections), and maintaining an audit trail (i.e., record of all research steps) with thick description (i.e., detailed record of themes).

\section{Results}

Across three phases (qualitative, quantitative, integrated), this sequential exploratory design provides data on environmental supports and barriers experienced by U.S. rural college students in one setting.

\section{Qualitative Phase (Research Question 1)}

The research team identified 20 primary themes and 129 meaning units, informing a structural description of four key areas: (a) factors influencing student success (Themes 1-5), (b) faculty practices for working with at-risk students in a rural college setting (Themes 6-9), (c) administrative issues for working with at-risk students in a rural college setting (Themes 10-14), and (d) president, cabinet, and board of trustees' vision for rural college setting (Themes 15-20). Table 2 provides a brief definition of each structural descriptor. Contact the first author for a complete description and associated quotes of the 20 themes. 


\section{Theme 1: Personal protective factors for at-risk college students.}

All six focus groups described the significance of students' personal protective factors that assisted in achieving success in college. Examples of the nine meaning units associated with Theme 1 include (a) involvement in university life, athletics, and employment; (b) meaningful service, connection, and community; and (c) family support. Student focus group participant 6's experience with having a supportive family prior to attending college was described as follows: “...my father went to a good four-year university, and my mother went to a community college. They had a big role in helping me prepare for school."

\section{Theme 2: Personal risk factors for at-risk college students.} All six focus groups described perceptions of personal risk factors that contributed to student failure in college. Examples of the 10 meaning units associated with Theme 2 include (a) students leaving because of on-campus party culture; (b) lack of student grit and resiliency; and (c) isolation. Administration focus group Participant 5's experience with students isolating and consequently dropping out was described as follows:

Students aren't checking in, one of us [administration] checks in a few times a semester... And they just get lost and isolated at times, and the consequence of that lost can be either they leave or they're asked to leave.

\section{Theme 3: Underutilized supportive services and} accommodations. Four focus groups detailed the need for students to utilize services and accommodations. Examples of the six meaning units associated with Theme 3 include (a) stigma associated with asking for help and utilizing resources; (b) student confusion as to the existence and location of resources; and (c) student initiative to engage with the university. Administration focus group Participant 6's understanding of the lack of student initiative to seek out and utilize work study was summarized as follows: "There were 600-some-odd students that qualified for work-study this year and only 56 of them were actually earning [work study wages]. . . 8.8\% of our first-year class, that was work-study awarded, were actually earning on it." 
Theme 4: Needs of high-achieving students. Two focus groups focused on the needs of high-achieving students. Examples of the six meaning units associated with Theme 4 include

(a) no interest in lower standards; (b) deeply connecting to a major leads to success; and (c) disappointment in low rigor and admittance of lower-achieving students. Faculty focus group Participant 7's perception of lowering of standards as compared to work at another university was described as follows:

[T] he content is half as much as I've taught at any other university. I had to tear my syllabus in half to teach here in terms of content. So, we used to do 10 [name of scholarly performance], now we'll do four, maybe.

\section{Theme 5: Authentic and meaningful relationships with} faculty. When processing factors contributing to college success, all six focus groups described the importance of authentic and meaningful relationships with faculty. Examples of the five meaning units associated with Theme 5 include (a) student expectation to be accepted by faculty; (c) sharing struggles with faculty creates connection; and (c) mentorship and one-on-one communication creates safety. Faculty focus group Participant 3's experience with connections being created with students through sharing struggles was described as follows: "Yeah, I don't have conversations with them about jobs. . . they talk to me about their roommates or their girlfriends. I don't know if it's my disposition, but they talk to me about everything."

\section{Theme 6: The unique nature of advising at-risk, rural, college} students. In discussing the unique needs of rural at-risk college students, five focus groups described the unique nature of advising. Examples of the nine meaning units associated with Theme 6 include (a) supporting vs. enabling at-risk students; (b) challenging students with a goal and ability mismatch; and (c) enormous advising commitment for first-generation college students and at-risk students. Faculty focus group Participant 2 's experience with creating authentic relationships and the time commitment associated with advising a large load of at-risk, rural college students was described as follows: 
Developing a truly authentic relationship with them so they talk to us outside of class. We have such limited capacity to do that for the numbers, and the introverts need a little bit more, you know it's like pushing ropes sometimes to get them to come along.... There's two of us for 300 students.

Theme 7: Academic standards and rigor. Four focus groups discussed perceptions of faculty academic standards and rigor as they relate to working with at-risk rural college students. Examples of the seven meaning units associated with Theme 7 include (a) standards are more salient than faculty compassion; (b) mixed messages regarding leniency; and (c) higher level of rigor associated with full-time faculty. Administration focus group Participant 2's perceptions of lowering academic standards were stated as follows:

I think you're doing folks a disservice by doing that [lowering standards based on student skillset].... It's really better for a kid to learn what it's like to fail in kindergarten, when the stakes are relatively low. [Imagine if] the first time I fail is when I've got two kids, a mortgage, a car payment, and all of a sudden we're homeless.

\section{Theme 8: Innovative strategies and interventions for helping} at-risk students. All six focus groups provided innovative strategies and interventions that faculty could utilize when helping at-risk, rural college students. Examples of the 13 meaning units associated with Theme 8 include (a) early intervention with student to triage appropriate accommodations; (b) faculty use of practical, hands-on learning experiences; and (c) precollege social and counseling support for firstgeneration college students. Administration focus group Participant 5's experience with the power of early intervention, was described as follows: "Music, theater, and dance is one [supportive major] that comes to mind. The students in those programs practically live in the [name of College Theater] and they have extremely high mono contact with their faculty."

Theme 9: Highly supportive and engaging faculty. Four focus groups provided in-depth detail regarding the highly supportive and engaging nature of faculty. Examples of the six meaning units associated with Theme 9 include (a) encouraging and educating students to be 
independent and responsible; (b) utilization of techniques to personalize the student relationship; and (c) understanding the unique needs of introverted and extroverted students. Faculty focus group Participant 2's experience with creating connections with students through a personal out-of-college get-together was described as follows: "Just for our department, we try to get together...The faculty will host [a get-together] during the summer, students will go over and eat with the faculty. Grad students will host parties once a month in summer."

\section{Theme 10: Changing systems creating disengagement and} confusion. All focus groups described the nature of chaotic university systems. Examples of the 10 meaning units associated with Theme 10 include (a) technological chaos, (b) duplication of services creating confusion, and (c) non-accessible services that are not centrally located. Faculty focus group Participant 6's perceptions of the technological chaos created by the university website issues were described as follows: "Our website fiasco [sigh], it's a huge, huge problem. As an advisor and faculty, I cannot find information about resources and know where to send students and know what's available. How the heck is a new student supposed to?"

Theme 11: Student violations and misconduct. Two groups discussed the extreme nature of student violations and misconduct. Examples of the four meaning units associated with Theme 11 include (a) repeat drug and alcohol offenders, (b) frequent student suspensions due to assault violations, and (c) insufficient staff for handling the number of on-campus student violations. Participant 6 of the administrative focus group discussed the institution-based expectation to do more with less and the consequent burnout amongst the participant's staff:

...494 individual students have come through our office for conduct [during the initial 11 weeks of the semester]. And that's conduct, not including lesser violations that happen in residence halls. So, this is alcohol, marijuana, assaults, vandalism, threat, other things like that. I'm red-lining my staff. And as soon as I lose one of them. . . I don't have a backup plan.

\section{Theme 12: The importance of the student weekend and night} culture. All focus groups described the importance of the student weekend and evening experience while attending a rural college setting. 
Examples of the five meaning units associated with Theme 12 include

(a) the need to keep out-of-state students engaged or they transfer,

(b) accepted and expected on- and off-campus party culture, and (c) isolation in dorm rooms due to perception that there is nothing to do. Administration focus group Participant 6's perceptions were described as follows:

[I]f we improved the culture here after 11 p.m. on a Thursday night, or between then and Sunday morning, more of our students might want to stay. But no matter what clubs or activities you offer. . . this is a different place at night.

\section{Theme 13: Residence hall directors and advisors key to student} support. While faculty and administration were seen as important to student support, all six focus groups described residence hall directors and advisors as the most important groups for ensuring timely student support. Examples of the six meaning units associated with Theme 13 include (a) residence hall advisors help first-generation students acclimate, (b) high school and college administration communication to ease student transition stress, and (c) peer mentoring to help with acclimation. Participant 3 of the student focus group discussed her experience of being a resident advisor and witnessing poor outcomes regarding students' attendance at campus events: "It's also the same people that come in, but it's more the social people that go to the programs, not like people that ... need the programming."

Theme 14: Highly collaborative college and town cultures. Two focus groups described the importance of having a collaborative college and college-town culture. Examples of the four meaning units associated with Theme 14 include (a) downtown culture works with students, (b) immersion in the college community supports students, and (c) certain majors are strong in collaboration. Student focus group Participant 3's work in the downtown area near the university and cluster programming was passionately described:

Where we're located, we work with so many communities downtown that expand us ... I've worked with Voices Against Violence, I've worked with the Humane Society in [city name]...All of these programs show what [university name] wants us to be. 


\section{Theme 15: Administration and faculty burnout and impairment.}

All six focus groups described how burnout and impairment affect both faculty and administration. This experience was conceptualized as coming from frequent cuts, absorption of roles, the unwieldy expectations of advising and educating at-risk students, and additional obligations. Examples of the four meaning units associated with Theme 15 include (a) faculty are overwhelmed and fatigued by multiple roles (e.g., marketing and recruitment), (b) too many students to provide one-on-one support, and (c) programming frequently losing resources. Faculty focus group Participant 1's experience with taking on the extra duties of marketing was described as follows:

There is no marketing happening for grad, so the enrollment stuff is happening because we're doing it as faculty, on a personal level. And that's getting back to how much [can we take on], right? Coming in here [the university] almost every weekend, feels like detention.

\section{Theme 16: Reduction in personnel and resources and the} increase of freshman class size. Four focus groups described the tension of reduction in college personnel and simultaneous increases in freshman class size. Examples of the five meaning units associated with Theme 16 include (a) faculty/student ratio is unsustainable, (b) university's false advertising of small class sizes and one-on-one support, and (c) university growth is not sustainable. Faculty focus group Participant 6's perceptions of the push to bring an unsustainable, more underprepared, class size without adding the adequate resources were stated as follows:

I think the push to bring numbers, we need bodies, we need people, and we need tuition dollars and we're not necessarily backing that up with resources. And we're bringing in students who are not at all prepared.

\section{Theme 17: Lack of diversity and limited services to support} diverse groups. All focus groups lamented the lack of efforts to create a diverse student body and the shortage of services to support diverse groups. Examples of the five meaning units associated with Theme 17 include (a) multicultural programming dependent on one person of color, (b) university services related to diversity constantly in flux, and (c) not 
enough diversity in faculty for students to identify with. Faculty focus group Participant 2's perceptions of the lack of university support for diverse groups were expressed as follows:

I was on Academic Affairs last year, and mid-year you do the severance and probation letters, and over and over again the kids we were seeing in that pool [of severance letters] were kids who were coming from Hispanic backgrounds or international students. I kept asking what supports were available for these students, and no one had an answer.

Theme 18: The forgotten student body. All six focus groups described populations that have been neglected in terms of services and recruitment. These groups included diverse students, graduate students, transfer students, disabled students, international students, out-of-state students, and commuting students. Examples of the six meaning units associated with Theme 18 include (a) graduate students are unsupported and disconnected, (b) campus inaccessible for physical disabilities, and (c) no support for international students. Student focus group Participant 5's perceptions of the campus being inconvenient for those with disabilities were stated as follows:

[T] his campus is difficult for people physically that are injured or have, like, an impairment. It's impossible to get around for people who use crutches. Oh heck no, this campus, you know, is just a hill. So, I don't know if that will ever be really solved...

\section{Theme 19: Different beliefs regarding which student groups}

to invest in. All six focus groups described perceptions as to which student groups should be invested in. Examples of the six meaning units associated with Theme 19 include (a) focus efforts on regional, rural, low-socioeconomic, and working, (b) need for resources for the majority student population, and (c) create resources for diverse groups. Faculty focus group Participant 1's thoughts on directing the university vision to the majority of its students' background demographics were stated as follows:

The vision coming out isn't committed to rural [students], right?

And for someone who works primarily with those kinds of students, 
they need to be included in that vision. The vision seems to be about the fulltime student who do[es]n't have a career, potentially isn't commuting, and is coming overtime to their studies.

Theme 20: New required curriculum. Two focus groups described the need for the college to develop curriculum aimed at assisting students in a nontraditional manner. Corresponding meaning units were (a) required diversity course, (b) required course on daily living, and (c) mixing purely freshman courses with upperclassman students. Faculty focus group Participant 7's thoughts on mixing purely freshman student courses with upperclassman students were expressed as follows:

... having freshman somehow get mentored by upperclassmen. Purely freshman classes ... there's this kind of social norming that it's still not cool to be in school [hmm] ... just to encounter upperclassman students...who are passionate about it.

\section{Quantitative Phase (Research Question 2)}

For the 86-question survey, the mean item responses ranged from 2.41 to 4.65 (SD range $=0.58$ to 1.30 ). Of the 86 survey items, $44(51.1 \%)$ had student response ranges between 0.75 and 1.00 for agree or strongly agree, which fell within Ruperto et al.'s (2008) acceptable threshold. Furthermore, these 44 survey items aligned with 18 of the original qualitative themes; these served as the 18 meta inferences. Three (3.4\%) student survey items had student response ranges between 0.75 and 1.00 for disagree or strongly disagree. These three survey items, representing two qualitative themes, demonstrated inconsistency between the qualitative and quantitative strands (see Table 2).

There were 39 (45.3\%) survey items and two qualitative themes that were considered midrange. Midrange themes and questions represent survey items (and related qualitative themes) for which students neither strongly (i.e., 0.75-1.00) agreed with nor strongly disagreed with on the student survey. The qualitative themes that were entirely midrange include (a) Theme 18 (the forgotten student body) and (b) Theme 20 (new required curriculum). 


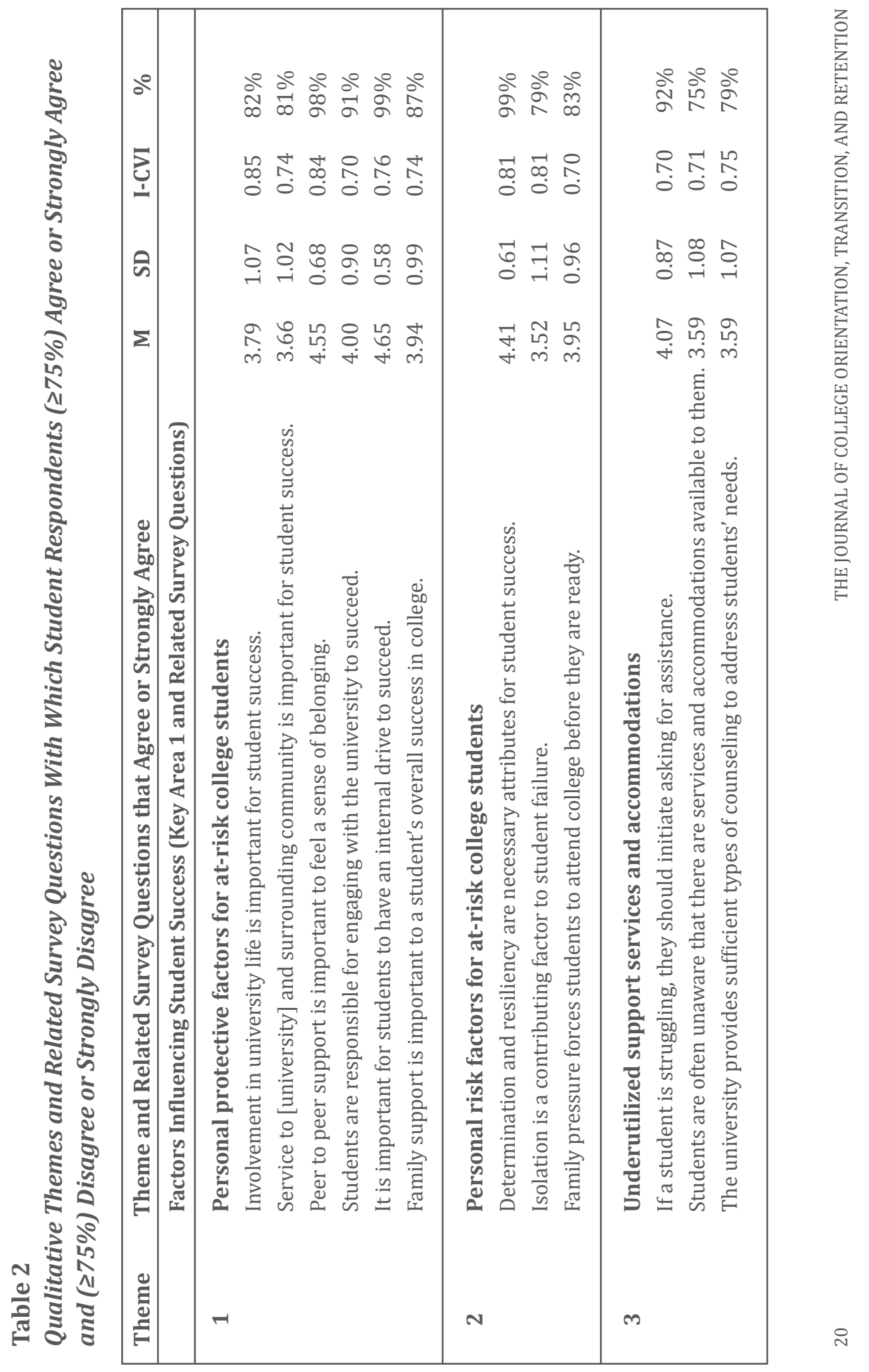




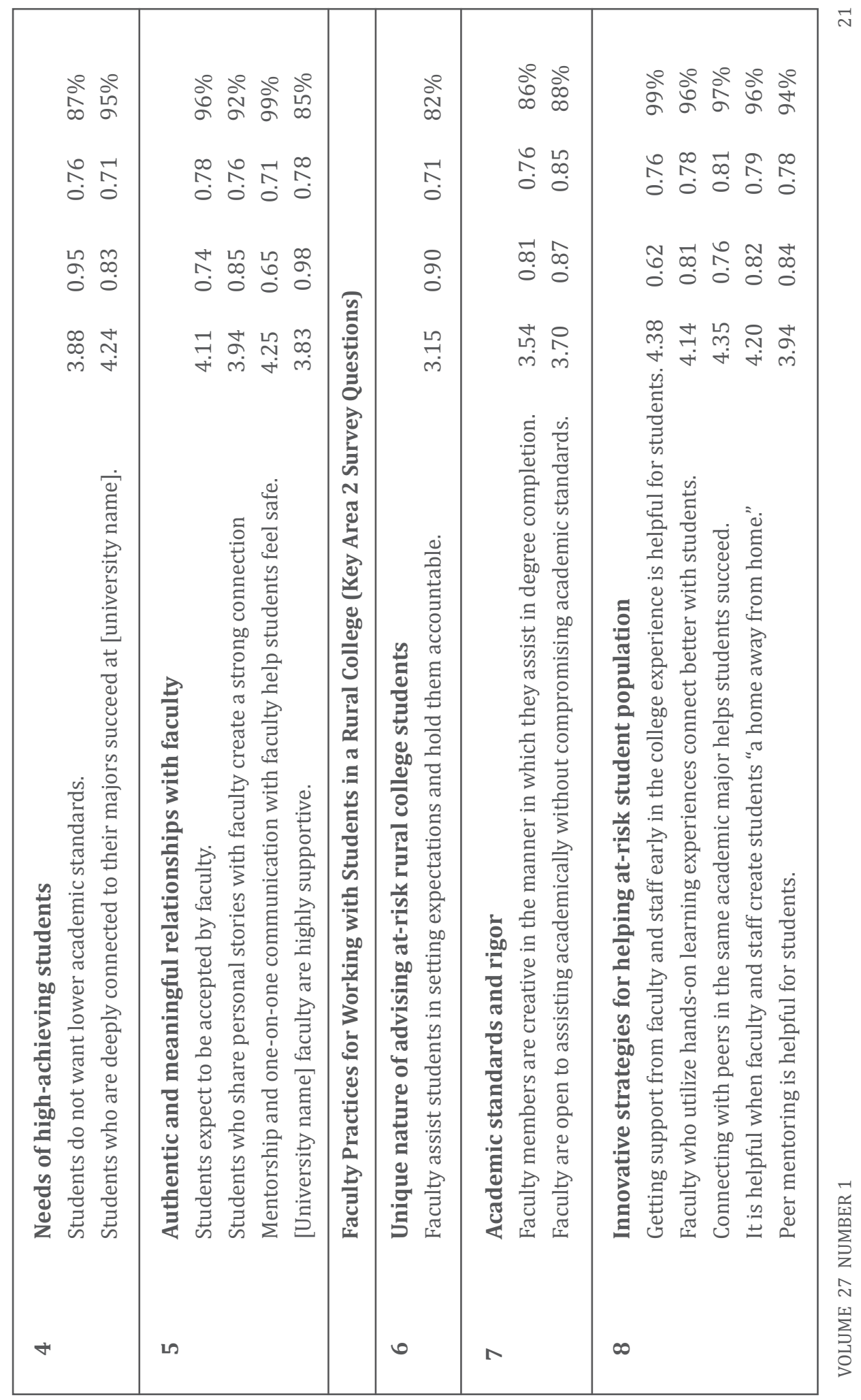




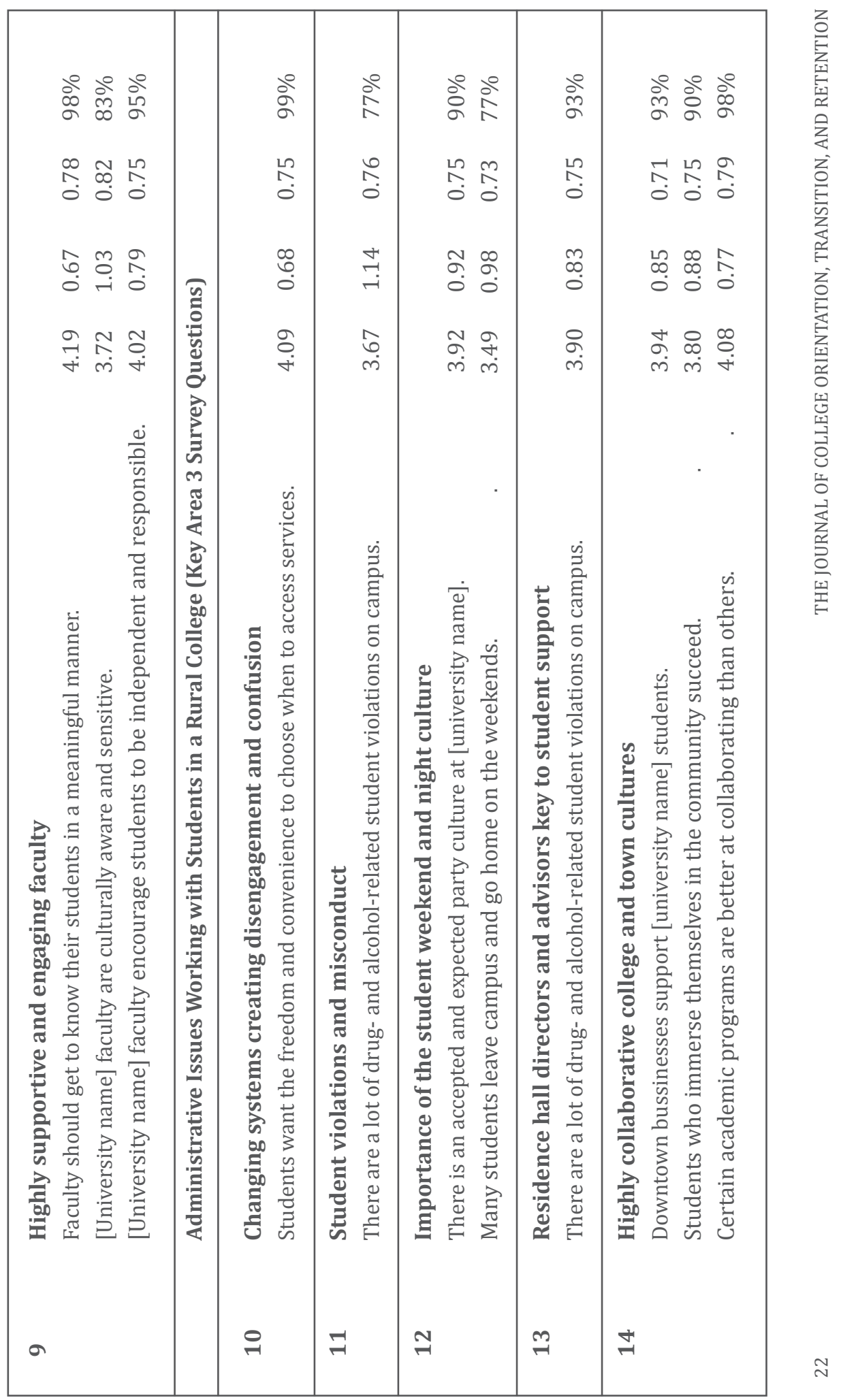




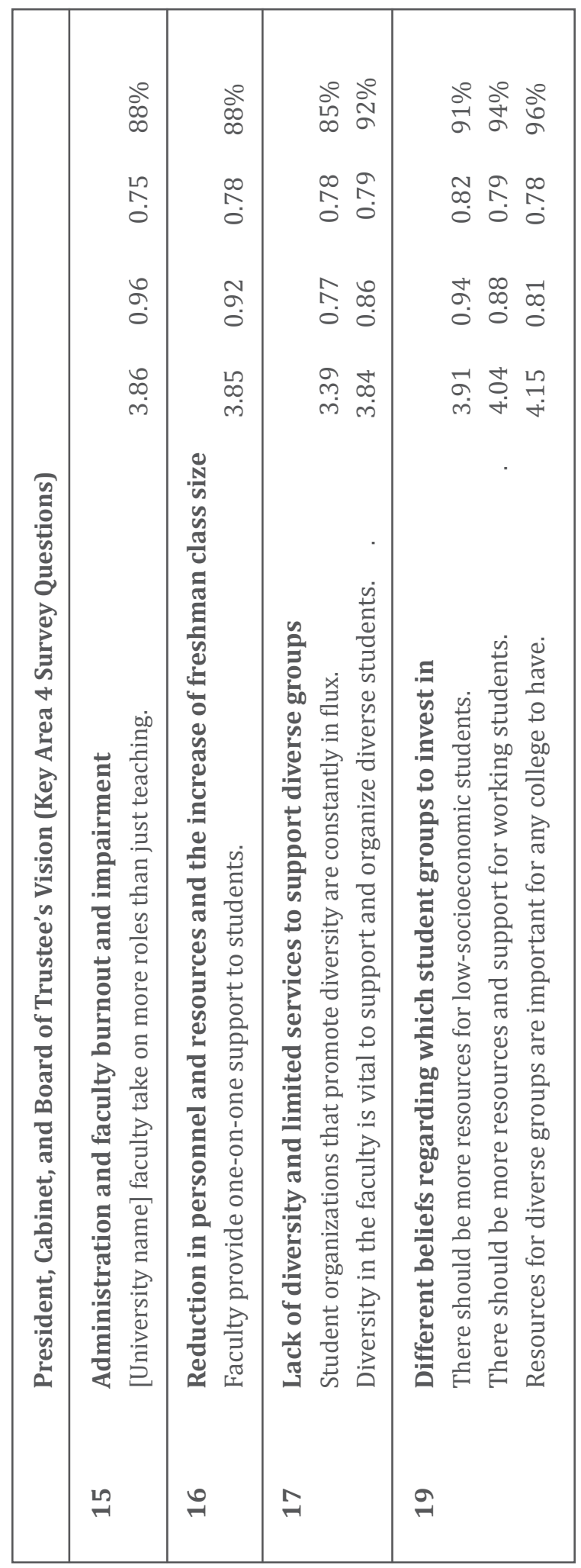




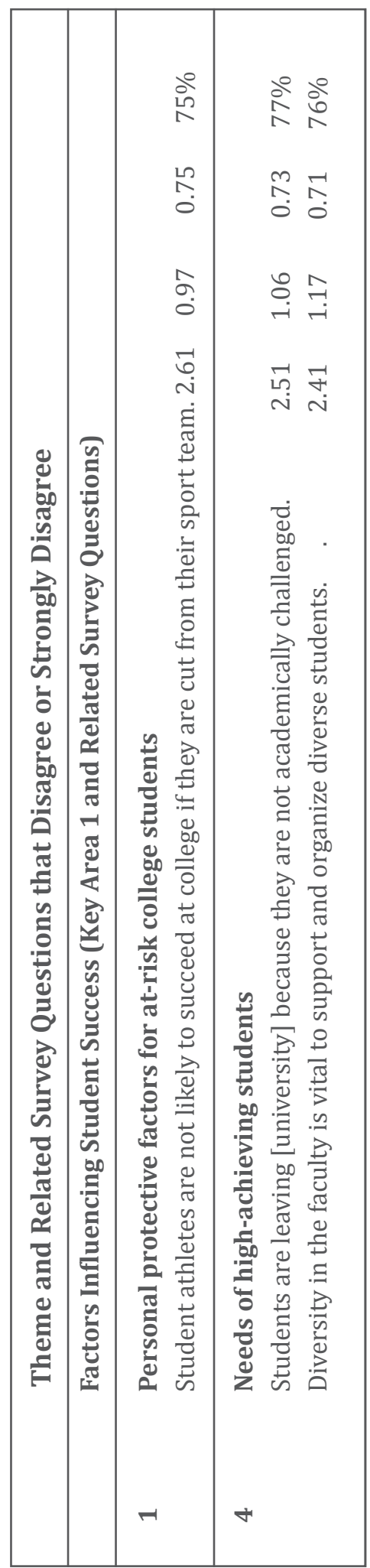

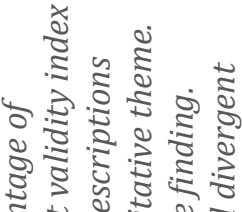

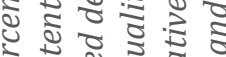

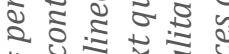

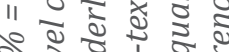

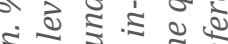

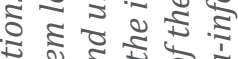

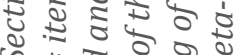

काI ป ०

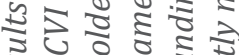

वั।

र

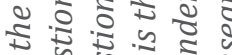

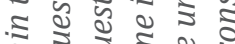

:

उे वे ह है

ปัँ

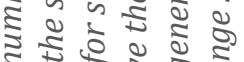

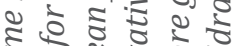

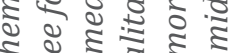

क

\& 유

๙

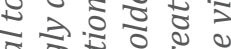

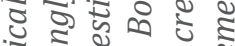

ปั

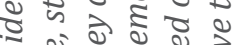

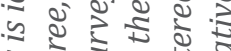

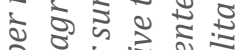

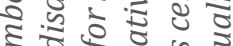

3.

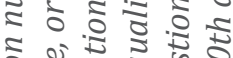

ฐ ข

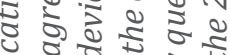

ज्ञ

ป

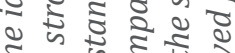

ह के की ई

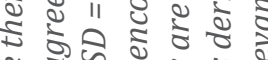

¿ 0 के है के

¿ปे

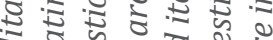

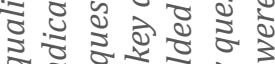

$0 . \Xi$ व वे पे

2 है के है हे है

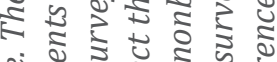

之. 


\section{Integrated Phase (Research Question 3)}

To ascertain meta inferences, the research team analyzed data for alignment of each survey question with the identified qualitative themes. The following are provided in Table 2: (a) foundational qualitative theme, (b) corresponding survey question(s), and (c) percentage of agreement attained from each student survey question. Survey items were excluded if less than $75 \%$ of participants rated a statement as agree/strongly agree or less than $75 \%$ of participants rated a statement as disagree/strongly disagree.

The research team tested the overall significance of the single factor used to categorize the survey items. Logistic regression revealed a nonsignificant fit $(\chi 2=4.4, \mathrm{df}=2, \mathrm{p}=0.11)$, indicating the single factor model represented the data well. Next, the research team interpreted the significance of the fitted parameter estimates. The model designated the first level as the reference level (accessibility and importance of educational and campus-based resources). For the other two levels, the research team fitted the parameters that represented adjustments to the intercept value. They identified the second parameter estimate as significantly different from zero, or that the adjustment in log-odds from the reference level to the second level (faculty and staff experiences, values, and interventions) was significant $(\mathrm{z}=2.047, \mathrm{p}=0.04)$. For the third parameter estimate, they found that the adjustment in log-odds from the reference level to the third level (needs, culture, and conduct of students) was nonsignificant ( $\mathrm{z}=1.682, \mathrm{p}=0.09$ ).

Relative to the odds associated with strong survey responses for the reference level of the one-factor model, the research team calculated the odds ratio of 3.89. This means, relative to the reference level, the odds of a majority strong response are almost four times greater for the second level. This suggests that participants are responding more consistently to questions related to faculty and staff experiences, values, and interventions (compared to reference level).

\section{Discussion and Implications}

Using multiple stakeholders as co-researchers and participants, this exploratory sequential study identified environmental supports and 
barriers for students attending a rural college. Specifically, 19 of the 20 qualitative themes, derived across six focus groups, were in alignment for a surveyed sample of rural college students, reflecting agreement of what supports and barriers effect rural college students. Logistic regression analysis indicated model fit, demonstrating that three broad categories of the survey items were appropriately clustered, yet distinct from one another. Similar to previous retention and persistence research (Fontaine, 2014; Marsh, 2014; Purdie \& Rosser, 2011; Roksa \& Kinsley, 2019), the results indicated the rural college experience is enhanced by small class sizes, relationships with faculty, accessible resources, daily assistance from peers, supportive family members, and involvement in university and community life.

Administration participants reported a primary focus on full-time, residential, undergraduate students. The student populations that appeared to be most underserved within this study context were those from diverse ethnic and racial backgrounds, those who were graduate students, and/or those who identified as one or more of the following student statuses: physically disabled, transfer, commuter, nonresidential, international, or out-of-state student. The student and faculty participants reported issues relative to this lack of attention, including (but not limited to): no transfer student orientation, campus buildings unsupportive of students with physical disabilities, and no diversity center(s). All focus groups emphasized the need for rural colleges to support at-risk students directly with classes and outreach efforts aimed at demystifying the university experience, teaching basic life skills, maintaining an accessible website, and providing a blueprint for on- and off-campus resources for diverse groups.

All stakeholder groups indicated that mentorship from fellow students was essential in helping at-risk students succeed. Consistent with previous literature (e.g., Collier, 2015; Newton, Ender, \& Gardner, 2010) and research (e.g., Fontaine, 2014; Yomtov et al., 2017), participants described the salience of academic peer mentoring and advising on how to navigate the social aspects of college. Similar to previous findings (e.g., Bloom, 2009), resident advisors and department administrative assistants 
were often described as the most critical in helping at-risk populations cope with nonacademic challenges. Resident advisors were often viewed as the most essential staff, although participants expressed a desire for meaningful bonds with peers and faculty to help with their adaptation to college.

Participants reported that faculty and administrative staff were viewed as most effective when they invested a significant amount of time in creating relationships with students, and students were successful when demonstrating extroverted traits. In fact, survey participants were almost four (3.89) times more likely to respond strongly to survey items related to faculty and staff experience, values, and interventions than to those related to the educational and campus-based resources. This served as an indication of the strength of interpersonal relationships. Faculty actions, akin to developmental advising (Crookston, 1972), that were recommended, while maintaining academic rigor and appropriate boundaries, include: creating meaningful relationships, being available for academic and emotional processing, supporting students in finding on- and off-campus resources, challenging students both personally and professionally, physically escorting students to particular resources, setting expectations, helping with financial aid paperwork, and extending additional efforts for introverted students.

Participants spoke to the combination of inefficient and understaffed resources and the student experience of boredom and isolation, due to limited weekend and nighttime services. This led to the participants labeling the university as a suitcase college. Faculty focus group members indicated that the lack of nighttime and weekend infrastructure encouraged students to transfer, especially those who were out-of-state students. Similar to past findings (Croxon \& Maginnis, 2006), participants desired that administration create university infrastructure that assists rural college students and subgroups (e.g., low socioeconomic status). These results are in line with research indicating the importance of student satisfaction with their college experiences (Webber, Krylow, \& Zhang, 2013). 


\section{Limitations and Areas for Future Research}

Several limitations should be considered when reviewing the present study. First, this investigation used a single university for the two study phases, limiting the generalizability to other rural institutions from diverse geographical regions. Second, a potential limitation is the issue of quantitized qualitative data; in this study qualitative data were quantitized during the survey development and logistic regression response variable categorization phases. Although quantitized qualitative data may be susceptible to loss of depth and flexibility or vulnerable to collinearity (Bazeley, 2004), CVI estimates and model fit indices seem to provide some evidence that these limitations may be minimal. A third limitation of the study was the survey response rate and sample composition. The survey served as an initial strategy for gauging whether survey items may be suitable for other populations and more specific sub-populations (e.g., first-generation college students) within rural college settings. Additionally, the sample composition slightly underrepresented the student population at the rural college on first-generation college status (i.e., $37 \%$ versus $43 \%$ ) and overrepresented the student population on racial and ethnic minority status (i.e., $12 \%$ versus $9 \%$ ).

Future analysis is needed on the survey itself, including factor analysis, construct validity, and criterion-related validity. Furthermore, larger studies with higher response rates are necessary to provide support for the identified supports and barriers. Additionally, the logistic regression analysis indicated that participants were nearly four times more likely to respond strongly to survey items related to faculty and staff experiences, values, and interventions. This finding suggests the benefit of exploring interpersonal relationships during college through interviews with at-risk student populations. Lastly, program evaluations into rural college resources could determine whether institutions have available resources for at-risk student populations and the degree to which barriers exist for particular types of students. 


\section{References}

Bazeley, P. (2004). Issues in mixing qualitative and quantitative approaches to research. In R. Buber, J. Gadner, \& L. Richards (Eds.), Applying qualitative methods to marketing management research (pp. 141-156). Palgrave Macmillan.

Beckowski, C. P., Gebauer, R., \& Arminio, J. (2018). Cultivating deeper life interactions: Faculty-student relationships in a nonresidential learning community. Journal of College Student Development, 59(6), 752-755. https://doi.org/10.1353/csd.2018.0070

Birx, D. L., Anderson-Fletcher, E., \& Whitney, E. (2013). Growing an emerging research university. Journal of Research Administration, 44(1), 11-35. http://download.srainternational.org/journal/archive/ JRA\%20V44n1_Spring2013-FINALpages.pdf

Bloom, L. R. (2009). 'When one person makes it, we all make it': A study of Beyond Welfare, a women-centered community-based organization that helps low-income mothers achieve personal and academic success. International Journal of Qualitative Studies in Education, 22(4), 485-503. https://doi.org/10.1080/09518390902740597

Bradley, P. (2012). Powered by Pell. Community College Week, 24(16), 6-7. Bryan, E., \& Simmons, L. A. (2009). Family involvement: impacts on postsecondary educational success for first-generation Appalachian college students. Journal of College Student Development, 50(4), 391-405. https://doi.org/10.1353/csd.0.0081

Collier, P. J. (2015). Developing effective student peer mentoring programs: A practitioner's guide to program design, delivery, evaluation, and training. Stylus Publishing.

Creswell, J., \& Plano Clark, V. (2012). Designing and conducting mixed methods research (2nd $E d)$. Sage.

Crookston, B. B. (1972). A developmental view of academic advising as teaching. The Journal of College Student Personnel, 13, 12-17. https:// doi.org/10.12930/0271-9517-14.2.5 
Croxon, L., \& Maginnis, C. (2006). Total learning environment and the implications for rural student nurse retention. Australian Journal of Rural Health, 4, 132-133. https://doi.org/10.1111/j.14401584.2006.00776.x

Davis, L.L. (1992). Instrument review: Getting the most from your panel of experts. Applied Nursing Research, 5, 194-197. https://doi. org/10.1016/s0897-1897(05)80008-4

Flynn, S. V., Duncan, K. \& Jorgensen, M. F. (2012). An emergent phenomenon of American Indian postsecondary transition and retention. Journal of Counseling \& Development, 90: 437-449. https:// doi.org/10.1002/j.1556-6676.2012.00055.x

Fontaine K. (2014). Effects of a retention intervention program for associate degree nursing students. Nursing Education Perspectives, 35(2), 94-99. https://doi.org/10.5480/12-815.1

Hamilton, L., Fogg, L., and Grimm, C. (2017). Challenge and hope in the North Country. The Carsey School of Public Policy at the Scholars' Repository, 326. https://doi.org/10.34051/p/2020.315

Hays, D. G., \& Singh, A. A. (2012). Qualitative inquiry in clinical and educational settings. Guilford Press.

Koh, J. P., Katsinas, S. G., Bray, N. J., \& Hardy, D. E. (2019). The “DoubleWhammy": How cuts in state appropriations and federal Pell Grants harm rural community college students and the institutions that serve them. New Directions for Community Colleges, 2019(187), 9-17. https://doi.org/10.1002/cc.20365

Lesnoff, M., \& Lancelot, R. (2012). aod: analysis of overdispersed data ( $R$ package, version 1.3). https://CRAN.R-project.org/package=aod.

Linley, J. L. (2018). Racism here, racism there, racism everywhere:

The racial realities of minoritized peer socialization agents at a historically White institution. Journal of College Student Development, 59(1), 21-36. https://doi.org/10.1353/csd.2018.0002

Lowinger, R. J., Kuo, B.C.H., Song, H., Mahadevan, L., Kim, E., Liao, K., YuHsin., Chang, C. Y., Kwon, K., \& Han, S. (2016). Predictors of academic procrastination in Asian international college students. Journal of Student Affairs Research and Practice, 53 (1), 90-104. https://doi.org/ 10.1080/19496591.2016.1110036 
Lynn, M.R. (1986). Determination and quantification of content validity. Nursing Research, 35, 382- 385. https://doi.org/10.1097/00006199198611000-00017

Marsh, G. (2014). Institutional characteristics and student retention in public 4-year colleges and universities. Journal of College Student Retention, 16(1), 127-151. https://doi.org/10.2190/cs.16.1.g Mbuagbaw, L., Bonono-Momnougui, R.-C., Thabane, L., Kouanfack, C., Smieja, M., \& Ongolo-Zogo, P. (2014). A framework for community ownership of a text messaging programme to improve adherence to antiretroviral therapy and client-provider communication: a mixed methods study. BMC Health Services Research, 14, 441. doi: 10.1186/1472-6963-14-441. https://doi.org/10.1186/1472-6963$14-441$

Moody's Investors Service (2012). US private college and university medians underscore revenue challenged and mixed outlook for sector. https://www.calvin.edu/admin/president/finances/docs/2012moody-private-college-university-medians-fiscal-year-2011.pdf Moustakas, C. (1994). Phenomenological research methods. Sage publications.

Newton, F., Ender, S., \& Gardner, J. (2010). Students helping students: a guide for peer educators on college campuses (2nd ed.). Jossey-Bass.

Purdie, J. R., \& Rosser, V. J. (2011). Examining the academic performance and retention of first-year students in living-learning communities and first-year experience courses. College Student Affairs Journal, 29(2), 95-112. https://doi.org/10.32469/10355/4710

R Core Team. (2013). R: a language and environment for statistical computing. R Foundation for Statistical Computing.

Ridenour, M. J. (2015). How do college students define college preparedness? School of Education Student Capstone Theses and Dissertations. 231. https://digitalcommons.hamline.edu/hse_all/231 Roksa, J., \& Kinsley, P. (2019). The role of family support in facilitating academic success of low-income students. Research in Higher Education, 60(4), 415-436. 
Ruperto, N., Meiorin, S., Iusan, S. M., Ravelli, A., Pistorio, A., \& Martini, A. (2008). Consensus procedures and their role in pediatric rheumatology. Current Rheumatology Reports, 10(2), 142-146. https://doi.org/10.1007/s11926-008-0025-6

Sandoz, E. K., Kellum, K. K., \& Wilson, K. G. (2017). Feasibility and preliminary effectiveness of acceptance and commitment training for academic success of at-risk college students from low income families. Journal of Contextual Behavioral Science, 6(1), 71-79. https://doi.org/10.1016/j.jcbs.2017.01.001

Selingo, J. (2013). College (un)bound: The future of higher education and what it means for students. Houghton Mifflin Harcourt.

Sriram, R., Glanzer, P. L., \& Allen, C. C. (2018). What contributes to selfcontrol and grit?: The key factors in college students. Journal of College Student Development, 59(3), 259-273. https://doi. org/10.1353/csd.2018.0026

Tashakkori, A., \& Teddlie, C. (2008). Quality of inference in mixed methods research: Calling for an integrative framework. In M. M. Bergman (Ed.), Advances in mixed methods research: Theories and applications (pp. 101-119). Sage.

Troiano, P. F., Vaccaro, A., Kimball, E. W., Moore, A., \& Newman, B. M. (2018). "Not gonna hold me back": Coping and resilience in students with disabilities. Journal of Student Affairs Research and Practice, 56(2), 181-193. https://doi.org/10.1080/19496591.2018.1506793

Webber, K. L., Krylow, R. B., \& Zhang, Q. (2013). Does involvement really matter? Indicators of college student success and satisfaction. Journal of College Student Development, 54(6), 591-611. https://doi. org/10.1353/csd.2013.0090

Yomtov, D., Plunkett, S. W., Efrat, R., \& Marin, A. G. (2017). Can peer mentors improve first-year experiences of university students? Journal of College Student Retention: Research, Theory, and Practice, 19, 25-54. https://doi.org/10.1177/1521025115611398. 